\title{
Teaching Management Strategies Formulated by Indian University Management during COVID-19
}

\author{
Sachchida Nand Shukla \\ Associate Professor, Department of Commerce, Central University of Kashmir, Ganderbal, India \\ sachchidanan@cukashmir.ac.in
}

\begin{abstract}
Leadership is somewhat a daunting task in higher education. It is excessively more challenging and demanding. Truly, leader has to act consistently with great wisdom and vision to influence its distinctive group of employees and arouse level of motivation in them to contribute their best in the accomplishment of institutional goals. Accordingly, due the effective leadership, higher education in India has undergone constructive changes over the last decade or so. It has seen a phenomenal proliferation of institutions to outreach an overwhelmed student community and other stakeholders. However, this whole discourse got diluted following the emergence of the Covid-19 pandemic. Primarily, the education system came to a total halt in India. The institutions were put off, and students were restrained from attending the institutions. Consequent upon, the students initially lost their sizable amount of time. While to the other extreme, the institutional leadership all across India was rephrasing how to deal with the situation. The thought process and collaborative institutional leadership evolved an overwhelmingly Philip -the teaching-learning system's online mode. This new education transmission approach through Covid-19 pandemic had inbuilt beauty in terms of human safety, physical distancing, and content dissemination. Nonetheless, this whole purposeful academic transaction is an outcome of many leadership strategies that were gradually put to practice to see the academic discourse virtually in execution. In this context, the paper is a modest effort to underline the design which leaders evolved through the covid-19 pandemic to push all the stakeholders of higher education to remain active for the cause they are meant for.
\end{abstract}

Keywords: Pandemic, Strategies, Academic, Leadership

\section{Introduction}

Earlier in March 2020, COVID -19 pandemic has brought the world to a standstill situation. It posed multiple threats predominantly to the life and livings of all individuals across the globe. In this hopelessness phenomenon, the driving forces for the people were still cheerful and proactive leadership. Unfortunately, such leadership was mostly invisible and absent. Consequent upon, the vast sectors of the economy suffered excessively, including higher education.Nevertheless, in this sector, the path-breaking leaders came on seen and visualized the challenge. They vociferously pressed the gradual positive inducement through the involvement of one and all with commitment and continuous improvement to sail through the turbulent times of pandemic and succeeded to a considerable extent. They changed the cantors of academic institutions and rightly the way of their working and bought the teacher- his knowledge, skills and attitude and, of course, the whole classroom to hometown and close to learners' kitchen. Moreover, the leadership attempted to address the psychological trauma of student community through the engagement of expert talk sessions on stress management, anxiety relaxing therapy modules and community help, selfhelp and self-management. This syndicate of leadership was somewhat uncommon to the past panorama. However, in the existing covid -19 pandemic, it gained wide adaptability in every nook and corner. There is hardly any part of the globe where pupils do not get benefitted from this leadership approach.

The higher education in India demanded an exemplary leadership approach and strategies from institutional leaders to deal with the unimaginable crises thrown by the covid-19 pandemic. These leaders had to crave a new work order that ushers the opportunities to learn for a vast student community of 23 million spread over 50 million-odd locations in the country. The whole discourse was daunting and challenging. Nevertheless, the following strategies that leaders overwhelmingly used instilled the difference.

- Safeguarding the safety of every stakeholder of education

- Instilling a sentiment to do something for the students in teachers

- Arousing sense of purposes to learn by whatever the means in students

- Pushing technology to work as a backend means

- Assessing the output and yield- measuring students satisfaction through continuous feedback

- Redesign of strategies and their execution

\section{Literature Review}

Leadership represents the interactions between leaders and followers through which leaders exert influence on organizations or followers to achieve goals. Leadership is closely related to safety performance and it has been investigated in safety research (Gracia et al., 2020; Xue et al., 2020). Leadership is the use of wisdom and power to command people in the organization to accomplish organizational goals. Nevertheless, the recent work of authors such as Abraham Zaleznik and Daniel Goleman has fundamentally changed the way we look at leadership, many of their themes were foreshadowed in W.C.H. Prentice's 1961 article rejecting the notion of leadership as the exercise of power and force or the possession of extraordinary analytical skill. Prentice defined leadership as "the accomplishment of a goal through the direction of human assistants" and a successful leader as one who can understand people's motivations and enlist employee participation in a way that marries individual needs and interests to the group's purpose. He called for democratic leadership that gives employees 
opportunities to learn and grow-without creating anarchy. The past research has attempted to underline the role of leadership in terms of popularity, power, showmanship, or wisdom in long-range planning .Some leaders have these things, but they are not of the essence of leadership. Leadership is the accomplishment of a goal through the direction of human assistants. The man who successfully marshals his human collaborators to achieve particular ends is a leader. A great leader is one who can do so day after day, and year after year, in a wide variety of circumstances (Prentice, 2004). However, the academic leadership came under daunting challenge in the wake of COVID-19 infections. As people adapt to new realities of work, managers in organizations play a critical role in shaping employees' experiences at work during and after crisis. Though in most organizations the physical connection between leaders and followers was interrupted to some degree by COVID-19, leaders - through their Fostering leader-follower attachment security level of communication and responsiveness to employee concerns - can still have a significant impact on follower behaviour, performance and emotional distress (Wu and Parker, 2017). In the year 2020, higher educations in India has experienced a rude shock in the shape of Covid-19 pandemic first of its kind following independence. In this contextFong et al., (2020) and Zenker and Kock, (2020) opine that the COVID-19 outbreak is considered to be an impactful incident and a major health crisis in world history and in December 2019, several cases of COVID-19 pneumonia were diagnosed in Wuhan, China, and then COVID-19 occurred in more than 200 countries and regions around the world.Although, a similar phenomenon was experienced by the world over a century before 1819 with the outbreak of Spanish flue. Nevertheless, in the Indian context, its ramifications were somewhat marginal. While during 2020, the students were forced to remain indoors, and institutions were closed. The academic discourse came to a halt for quite a long time. A sizeable amount of valuable time was lost by students and teachers. The teaching-learning process appeared a nightmare. According to data released by the UNESCO on 25 of March schools and universities closures dueto COVID-19 were implemented nationwide in 191 countries and affected over 1.5 billion student's worldwide, accounting for $87 \%$ of enrolled learners. Another report released by UNESCO and $\mathrm{CNN}$, the learning of approximately 1.6 billion students has been interrupted by the closures of education institutions around the globe. The COVID-19 pandemic like elsewhere in the world, has negatively impacted the education of millions of students. It has had impact on social mobility whereby schools are no longer able to provide education. The impact of long term school closure is yet to be seen. On account of this panorama, the academic leaders initially were caught up in great pessimism about what to do and how to fillip the teaching-learning process under these exceptional situations? Thereby drawing the clues from the concept "work from home" the online teaching learning process evolved with active backend support from the technology and intranet etc. The academic leaders gave a new model of teaching-learning process which largely is at par with a real one. The model has proved excessively effective and there are many higher education institutions in the world who are contemplating to make this model a regular feature in the post free covid-19 times. The countries like Iraq, Georgia, china, US, Uk and India have pushed officially institutional leaders to engage students through online platform. This strategical move enabled the academic leaders to stay relevant to time and rise up to the expectations of the stakeholders. Moreover, the academic leaders restored the other institutional activities and conducted online examinations, organized webinars, expert talks, stress management sessions etc. The academic leaders learned to behave differently during the COVID-19 pandemic from the experiences and strategic discourses of other industrial leaders like Microsoft, Facebook and other large corporations of China, like Alibaba, Baidu, Bank of China, JD.com, Tencent and Xiaomi set up makeshift assembly lines to produce additional masks and disinfectants. LVMH shifted production in its perfume factories to produce hand sanitizer, which it then delivered to French health authorities and hospitals free of charge. Independent brewer BrewDog is using its distillery to produce sanitizer for those in need, as are French beauty companies L'Oréal and Coty. Similarly,Inditex, owner of Zara, manufactured hospital gowns in its clothing factories, and also donated masks to patients and health officials in Spain. Miroglio Group, an Italian textiles firm, is making face masks that meet medical requirements, producing up to 75,000 a day if needed. Chinese apparel manufacturers Erdos and Cabbeen are volunteering to convert clothing production for masks and protective suits. Alike to this, Meggitt is leading a consortium of organizations (including GKN, Thales and Renishaw) to adapt aerospace oxygen converter factories for ventilator production, while Italian car makers, Ferrari and Fiat Chrysler are supporting the nation's biggest ventilator manufacturer to boost production (www.google.com).

Closely learning from the efforts of the leaders of these great corporate houses, academic leaders no way remained behind during the covid -19 pandemic. They succeeded to arouse the interest in the students to learn under all circumstances and embedded a hybrid work place model for facilities. Moreover, they attempted to reach out to society by generating awareness in them how to safeguard themselves from the contagious covid-19 infections. These moves were quiet consistent to one undertaken by many leaders of tech companies like Facebook, Twitter, YouTube and TikTok have pledged to remove coronavirus conspiracy theories. Pharmaceutical companies (including Novartis, Bayer, Teva and Mylan) have pledged nearly 220 million chloroquine and hydroxychloroquine tablets for the global COVID-19 response. ByteDance is offering free use of its online workspace app for three years for NGOs, hospitals and medical institutions in China.Baidu created a map layer showing real-time locations of confirmed cases of the virus to better inform travellers in China.LinkedIn is offering 16 of its online learning courses for free, including sessions on staying productive, building relationships when you're not face to face, using virtual meeting tools and balancing family and work dynamics.Pfizer's Chief Medical Officer is sharing facts and personal tips on short social media videos to deal with covid-19 on twitter. Similarly Amazon announced unlimited paid sick leave over the next month for those who test positive for covid-19.JD.com and Alibaba launched a talent-sharing platform for those in affected sectors to find work in flexible job openings in e-commerce and supermarkets 
(www.google.com). These all exemplarily approaches enlightened academic leaders and motivated them to embed a new strategic approach for the higher education. Accordingly, they rolled out host of measures or strategies to rejuvenate higher education in the mid of 2020. Therefore, the present paper is a humble effort to underline the strategies which academic leaders filliped during the covid-19 to retore academic order and activity.

\section{Objectives}

The main objectives of the study were

- To study how the leaders evolved the online teachinglearning system during the emergence of COVID-19

- To examine the nature of strategies which academic leaders used to making online teaching-learning system possible

- To understand the response to the online teachinglearning system of all the stakeholders of education

- To study how far theacademic leaders succeeded to sail through Covid 19 pandemic to deal with challenges thrown to the higher education sector

\section{Methodology Design}

The study is a descriptive discourse based on the factual understanding, introspection and analysis of strategical discourse which academic leaders displayed during the COVID-19. Accordingly, the study is designed and compartmentalized into two section part I and Part II. Wherein, the part I of the study puts forth the introduction, literature review, objectives and methodology design of the study. While the part II presents a detailed discussion on the leadership strategies pursued by the academic leaders during the covid-19 pandemic and conclusion of the study.

\section{Discussion and Analysis}

Leaders set new trends and bring phenomenal changes in organizations. They dismantle blockades through policy strategic interventions and lead people to attain their goals. The same was somewhat seen in higher education in India in general and UT of Jammu and Kashmir in particular, where institutional leaders devised wonderful strategies to reach out to every student during the COVID-19 pandemic. The following were the main strategies adopted by the leaders during the covid-19 vis-à-vis higher education in the Union Territory of Jammu and Kashmir

\section{1) Reached out to the student community}

Initially, academic leaders were grappled by the lockdown however, the work from home concept when extended to higher education changed and relaxed the cantors of higher education. Factually, prior to Covid-19 pandemic, higher education in India has predominantly lagged behind to disseminate through technological intervention in teaching and learning process. The phenomenon is excessively responsible for low quality education and research. Nonetheless, technological intervention in few higher educational institutions was limited to few aspects only. In this context Christropher (2014) says that the Enterprise Resources Planning (ERP), Student Information Systems
(SIS), Learning Management Systems (LMS), etc have been penetrated in India in few higher education institutions with limited operations including admissions, fee payments, course planning and scheduling, faculty and other teaching resource management, learning material distribution, student information tracking, etc, but the basic teaching-learning process remains largely the same as was 50 years before. Reportedly, many higher educational institutions in India use LMS platform to post learning material to the students which in true sense has proven worthless and less effective for students. The system largely failed to replace the real teacher on the seen. However, in the covid-19 pandemic, higher education institutions were closed down and there remained no scope for direct teacher -student classroom interaction thereby engaging students in on line mode became necessity of the time. Accordingly, educational leaders across India cobbled their resources and filliped online education system to stay relevant to time and rise upto the situations during the covid-19 pandemic. This platform for teaching learning system is growing worldwide and in India, it is witnessing a steady growth rate of 25 percent year-on-year and is projected to be a $\$ 1.96$ billion industry by 2021 . With a network of more than 1.5 million schools and 18,000 higher education institutes, the market for digital education in India is enormous. Today, digital learning is no longer a luxury but implementation of digital tools of learning has become a necessity in schools. In the covid-19 the institutional leaders reached out to a vast majority of students through online mode and they spectacularly succeeded to arouse sense of purposes and interest in students community towards the academics through motivational talks. A study by (Choudhary, 2020) revealed that significant number of students in India had turned aloof towards their studies due to the excess covid stress. It were the teachers who pulled out the vast majority of students from hopelessness and brought them on the academic track and aroused in them a sense to do something even in these odd times when life and living was almost nightmare. This was also put on record and overwhelmedly acknowledged by the student communities. Through their empathic approach, the academic leaders with help of learned faculties managed to disseminate knowledge in the students who gradually defeated the negativity of the covid19. In this context, the Sloan Consortium reports 6.7 million student in higher education took at least one online course The growth rate of online enrollment is $300-400 \%$ that of classroom enrolment. The response of the students to online classes was spectacular. The student community were overwhelmingly benefited.

\section{2) Pushing Technology to Work}

Technological infusion is at the low ebb in higher education in India right since the beginning of independence, despite the fact that the government of India has initiated various measures time to time to bring desired technological changes and quality improvements in higher education. Consistent with this, New Education Technologies (NET) is expected to help both the teachers and students. With the advent of the internet, students overwhelmingly are using various means which predominantly include e- learning. to seek knowledgeindependently to stay abreast.In this context, Jonassen \& Reeves, (1996) says thatnew education technology (NET), by their very nature, are tools that 
encourage and support independent learning. Students using NET for learning purposes become immersed in the process of learning, and more and more students use computers as information sources and cognitive tools. Learning approaches using NET provide many opportunities for constructive learning through their provision and support for resource-based, student-centred settings and by enabling learning to be related to context and to practice (Berge, 1998). Nevertheless, these means proved deficient during the covid -19 pandemic to meet the academic needs of students. Realizing the potential knowledge gap in the existing platforms, the academic leaders pushed technology to work with the IT experts and faculty backend support. Initially, it appeared quite daunting for the faculty and students to get audient with the new technology and learn its operation. However, with time their familiarity enhanced with education technology. Today, the terms online learning, open learning, web-based learning, computer mediated learning, blended learning, machine-learning have emerged as a vital medium of teaching -learning process and all have common the ability to use a computer connected to a network, that offers the possibility to learn from anywhere, anytime, in any rhythm, with any means" (Cojocariu et al., 2014). In this context, Aakash (2020) hints that the online learning or e-learning industry in India is a prolific one, witnessing a steady growth rate of 25 percent year-on-year and is projected to be a $\$ 1.96$ billion industry by 2021 . With a network of more than 1.5 million schools and 18,000 higher education institutes, the market for digital education in India is enormous. Today, digital learning is no longer a luxury but implementation of digital tools of learning has become a necessity in schools.

Rightly, online teaching learning can makes the teachinglearning process excessively student-cantered, innovative, and flexible. Online learning can be transacted synchronously or asynchronously using different devices (e.g., mobile phones, laptops, etc.) with internet access. A students can learn independently and interact with instructors and other students" (Singh \& Thurman, 2019). Consistent to this, universities around the world have fully digitalized their operations under the present circumstances. Online learning is emerging as a victor ludorum amidst this chaos. Therefore, the quality enhancement of online teaching-learning is crucial at this stage. Online education in Chinese universities has increased exponentially after the Covid-19 outbreak. There was an overnight shift of normal classrooms into e-classrooms, that is, educators have shifted their entire pedagogical approach to tackle new market conditions and adapt to the changing situations. During this tough time, the concern is not about whether online teaching-learning methods can provide quality education, it is rather how academic institutions will be able to adopt online learning in such a massive manner and how they would remain relevant to time, situation and crises says Carey ( 2020) .Nevertheless, it can't beundermined that Elearning fulfils the needs of today's learners at their own comfort and requirements. Thus it has proven to be fruitful because of various reasons. It can be availed at any time at the learner's own convenience by purchasing the subscriptions of different platforms or logging in to access the courses (Colchester et al., 2017). It can share and offer teaching-learning materials in diverse formats such as slideshows, audios, videos, PDFs, e-mails, word documents and so on. Webinars and direct communications with teachers via various chat forums or messaging is also an open option in E-learning process. It offers free access to certain e-manuals like PDFs. It provides clear, easy, gradual instructions for better understanding of the learners. It is often regarded as the most suitable way for self-learning. It provides a wide range of materials for the learners that covers almost all topics and doubts (Bajaj and Sharma, 2018).

\section{3) Assessing Academic output and students Satisfaction}

The academic leaders during the covid-19 pandemic were concious of the fact that online teaching learning discourse is not option but a compelling necessity. Therefore, they were left with no chance to make it effective and upto the expectations of the all stakeholders especially for students. Initially, the daunting challenge for them was to fillip online mode of education system into operation through the active participation of students-faculty and backend technology. Nevertheless, with the gradual universalization of online education, the question of quality, productivity, student engagement and satisfaction came on fore. Therefore, to address these interlinked issues the academic leaders developed a robust mechanism to evaluate the productivity and quality outcome of online education during the covid-19 pandemic. They collected online feedback and mailed questionnaires to students to understand the fallicies and benefits of the new system. Consistent to this the research of Terra et all (2020) have found that remote learning is equally good to face to face or inperson learning system. In online learning, participants are dispersed geographically and learn at different times (asynchronous) with visual contacts are few or non-existent. The research of (Terra et al, 2020) shows that online learning prioritizes interaction to provide opportunities for students to apply concepts that have been obtained with unlimited time in class meetings. The use of online collaboration tools, such as online forum has potential to facilitate the interaction of participants and group activities in a web-based learning environment, and allow students to share discussions and ideas. Participation in interaction among students increases in internet-based activities rather than traditional classes. Moreover, the research has shown that online teaching facilitates student student interactions that usually takes place between individual students or when the students are assigned to work in a small group. This discussion can be synchronous discussion and asynchronous discussion. The synchronous discussions are exclusively conducted online only and students draw huge benefits and it promotes learning effectiveness. Many studies show that interaction can increase learning outcomes; one of them is cognitive understanding and high order thinking. Learning materials can be better understood by collaborative learning and interaction. Interaction in discussion forums exist in a variety of online learning platforms, such as e-learning platforms (Edmodo, Moodle, etc.) or mobile platforms (Line, WhatsApp, etc.). Online forums provide opportunities for students to not only cooperate but also collaborate to develop knowledge. Online interaction leads to social presence in course. Social presence had been identified to be a factor in enhancing quality of learning. Previous study found that interactions are a key element for successful 
learning experiences in online learning environment On the contrary, LaPointe \& Gunawardena found no evidence for a positive relationship between interaction and perceived learning outcomes (Terra et al, 2020).

\section{4) Redesign of Strategies and their Execution}

The academic leaders are constantly involved to work out the best strategies to engage students effectively and efficiently during the COVID-19 pandemic and they review the existing strategies and redesign the new strategies in the light of review results. Earlier, the LMS platform was used to post the lecture and content to the studentsand it was the sole responsibility of the students to read the study material and understand the same. Nevertheless, now it is relatively least used platform for online education. Academic leaders are now using Google classroom, Webex, Zoom platforms to transact the education which is equally effective to classroom education.

\section{Implications of the Study}

The study would prove very useful for the policy makers who are strategizing how to push advanced technology in higher education especially for online teaching learning process. Moreover, it will act as an embedded study and may provide insight to the researchers for further research. Further, the study opens a new area of research which would contribute in the long run towards the technological infusion and improvement in higher education.

\section{Limitations of the Study}

The study is limited in scope in the context of Jammu and Kashmir, where the internet gag and low connectivity is overwhelmingly experienced by the students and faculty. This may have affected the transmission of online education and strategies adopted by academic leaders, such effects have not been studied in this research. Further, the study examined the impact of only some vital strategies and not all other strategies which also may have influence on online teaching learning process in higher education.

\section{Conclusion}

Higher education in general and students in particular have been enormously benefited through the strategies of academic leaders that were pushed to transact education during the COVID-19 pandemic.

\section{References}

[1] Bajaj, R.V., \& Sharma, V. (2018). Smart Education with artificial intelligence based determination of learning styles. Procedia Computer Science, 132, 834842.

[2] Berge, Z. (1998). Guiding principles in Web-based instructional design.Education Media International, 35(2), 72-76.

[3] Carey, K. (2020). Is everybody ready for the big migration to online college? Actually, no. The New York Times. https://www.nytimes.com
[4] Choudhary, R. (2020). COVID-19 Pandemic: Impact and Strategies for Education in India. https://government.ecomictimer.indictimes.com/tag/edt ech

[5] Christopher, D. (2014). The Successful Virtual Classroom: How to Design and Facilitate Interactive and Engaging Live Online st Learning (1 ED). ISBM 13: 978-0814434284: AMACOM Publication.

[6] Cojocariu, V.-M., Lazar, I., Nedeff, V., Lazar, G. (2014). SWOT analysis of e-learning educational services from the perspective of their beneficiaries. Procedia-Social and Behavioral Sciences, 116, 1999 2003

[7] Colchester, K., Hagras, H., Alghazzawi, D.M., \&Aldabbagh, G. (2017). A Survey of Artificial Intelligence Techniques Employed for Adaptive Educational Systems within E-Learning Platforms. Journal of Artificial Intelligence and Soft Computing Research, 7, 47 - 64.

[8] Fong, L.H.N., Law, R. and Ye, B.H. (2020), “Outlook of tourism recovery amid an epidemic: importance of outbreak control by the government", Annals of Tourism Research, p. 102951

[9] Gracia, F.J., Tomas, I., Martínez-Corcoles, M. and Peiro, J.M. (2020), "Empowering leadership, mindful organizing and safety performance in a nuclear power plant: a multilevel structural equation model", Safety Science, Vol. 123, pp. 1-9

[10] Jonassen, D. and Reeves, T. (1996). Learning with technology: Using computers as cognitive tools. In D. Jonassen (Ed.):Handbook of Research Educational on Educational Communications and Technology (pp 693-719). New York: Macmillan.

[11] Singh and Thurman (2020) quoted in Impact of Online learning: Higher Education

[12] W A Terra1, S Wonorahardjo and S Suharti( 2020) "Analyzing types of interaction in nuclear magnetic spectroscopy online discussion forums that affects student learning outcomes" Journal of Physics: Conference Series 1465 (2020) 012055 IOP Publishing doi:10.1088/1742-6596/1465/1/012055

[13] W.C.H Printice( 2004) Understanding Leadership, Oxford Business Review

[14] Wu, C. and Parker, S. (2017), "The role of leader support in facilitating proactive work behavior: a perspective from attachment theory", Journal of Management, Vol. 43, pp. 1025-1049.

[15] Xue, Y., Fan, Y. and Xie, X. (2020), "Relation between senior managers' safety leadership and safety behavior in the Chinese petrochemical industry", Journal of Loss Prevention in the Process Industries, Vol. 65, pp. 1-15.

[16] Zenker, S. and Kock, F. (2020), "The coronavirus pandemic: a critical discussion of a tourism research agenda", Tourism Management, Vol. 81, pp. 1-4. 